\title{
A REPRESENTAÇÃO DE MENDIGOS EM OBRAS DE ARTISTAS
}

MARIANE D'AVILA ROSENTHAL rosenthal.mariane@hotmail.com

EDUARDA AZEVEDO GONÇALVES dudagon@terra.com.br

\author{
Mari Lucie Loreto \\ Mari_Lucie@hotmail.com
}

\section{Grupo De Pesquisa DESLOCC - CNPq/UFPel}

\section{RESUMO}

Representar a figura de "Mendigos" se constitui em uma forma de pensar e produzir artisticamente algo que seja uma imagem acordada com a cotidiana realidade, contextos sociais e artísticos e por questões poéticas podendo inclusive envolver aspectos particulares da vida do artista e desses grupos sociais que vivem em indigência ou mendicância material que se relacionam a condição de habitantes andarilhos, maltrapilhos, "sem teto" ou "sem abrigo". Os processos, a tecnologia, a materialidade, a linguagem escolhida pelos artistas e as diferentes maneiras de "dar a ver" essa vulnerabilidade social desde remotos tempos na linha histórica da arte mostram que a temática em torno dessa condição social não se esgota. Neste trabalho apresentamos algumas obras dos artistas Vincent Van Gogh, El Greco, Pieter Brughel, Bartolomé Esteban Murillo, Rembrandt Van Rijn, Pablo Picasso, Francisco de Goya y Lucientes, Honoré-Victorien Daumier, Lasar Segal, Diego Rivera e Dorothea Lange. Podemos observar que a vulnerabilidade e condição de risco social estão relacionadas a construção estética dos mendigos, proporcionando que sejamos capazes de observa-los através da historia da arte como figuras urbanas marginalizadas, relacionadas a um contexto de exclusão, marginalização ou indigência social por razões socioeconômicas e que transitavam e transitam próximos a centros urbanos. Desta forma, o artigo tem por objetivo mostrar esta temática associada também a produção de artistas contemporâneos como Mathieu Pernot e Francys Allys, revelando um outro sujeito que mendiga e que é classificado como "PESSOA EM SITUAÇÃO DE RUA" valendo destas figuras como elementos visuais que intrigam e provocam dentro de um contexto de descompromisso e insalubridade.

PALAVRAS-CHAVE: Cartografia. Deslocamento. Poética. Arte Contemporânea 


\section{INTRODUÇÃO}

A linha da História da Arte (HA) conduz a figura pitoresca dos mendigos e ao observarmos a produção artística associada, verifica-se que inúmeros foram e são até hoje os artistas que se apoderaram da temática em torno do risco e da vulnerabilidade social que versa sobre as "Pessoas em Situação de Rua".

As representações do mundo social estão relacionadas a construção estética relacional dos mendigos, proporcionando que sejamos capazes de observalos através da HA como figuras urbanas marginalizadas, relacionadas a um contexto de abandono, exclusão, marginalização ou indigência social por razões socioeconômicas, que transitavam e transitam próximos a centros urbanos.

Inusitadas e exóticas, sublimes e ao mesmo tempo inigualáveis, a figura dos mendigos vem acompanhada de uma estética sem que existam imposições, modismos ou conceitos.

Este conteúdo, através de diferentes formas de representação do corpo a partir de linguagens visuais, incluindo a pintura, escultura, gravura, fotografia, etc. foi abordado e conduzido se estendendo até a arte contemporânea, fazendo com que não se esgotasse por si só através das diferentes formas de dar a ver, a produção artística de alguns artistas que se valeram e se valem destas figuras como elementos visuais que intrigam e provocam dentro de um contexto de descompromisso, insalubridade e ausência aparente de controle social. Porém, observa-se que a essas linguagens foram incorporadas novas formas de dar a ver, como por exemplo, as instalações, objetos, livros de artista, etc..

Representar a figura pitoresca de mendigos na HA se constitui em forma de pensar e produzir artisticamente algo que seja uma imagem acordada com a cotidiana realidade social referente aos períodos artísticos em que esses grupos sociais que vivem em indigência ou mendicância material se relacionam a condição de habitantes andarilhos, maltrapilhos, sem teto ou abrigo, homeless, beggars, clochards, etc..

\section{DESENVOLVIMENTO E DISCUSSÃO}

Buscando algum significado filosófico para o termo "mendigo", encontra-se a citação de TIBURI (2011) que aqui está disponibilizada ao leitor deste artigo: 
A população das ruas das grandes cidades é composta de habitantes (ou desabitantes) provisórios ou não, que estão ali por motivos diversos. Muitas vezes são afetivos. Não é raro encontrar ricas histórias de vida entre as pessoas sem morada, desde aquele que renunciou à vida burguesa por considera-la insuportavel, até quem por meio de inesperadas leituras filosóficas criou um significado para o ato de "habitar" a transitoriedade, ou seja, "desabitar" intransitivamente e estar assim, na mera existência (TIBURI, 2011, http:/revistacult.uol.com.br/home/2011/03/ninguém-moraonde-não-mora-ninguem/).

Desta forma algumas figuras pitorescas adquirem um visual relacionado ao isolamento e/ou empobrecimento social, cujas causas estão elencadas na citação:

As razões socioeconômicas do aumento da população pauperizada e, com frequência, marginalizada durante os anos 1570-1650 são bem conhecidas: o empobrecimento de uma parte importante dos camponeses, causado pelo crescimento demográfico; a repetição das crises cíclicas, que conduzem os que buscam pão e trabalho em direção às cidades; a pauperização presente nas cidades, causada pela diminuição dos salários reais, devido ao aumento dos preços, e pela impossibilidade da incorporação dos novos imigrantes às estruturas artesanais e gremiais. Em toda a Europa, as conseqüências são similares: por um lado, o aumento do número de vagabundos e mendigos, além do limite de tolerância aceitável pelas autoridades estatais ou das cidades, e, por outro, a multiplicação das áreas perigosas, dentro ou fora das muralhas das cidades (ROGER CARTIER, P. $5,2014)$.

Independente da nacionalidade e da regionalidade do artista apreciando as imagens referentes a mendigos na $\mathrm{HA}$, observo que elaboram uma estética cuja imagética é ressaltada como figuras de destaque ou em segundo plano, marcada por uma visualidade superficial com pontos característicos, observados a partir do cotidiano, como por exemplo: a) representação como andarilhos, marginalizados, sujos, submissos e desalinhados; b) Utilização de vestimentas desgastadas; c) Sobreposição de vestimentas, conferindo camadas; d) Semblante emocionalmente deprimido e olhar melancólico; e) Estrutura corporal curvada; f) Apropriação de objetos, estruturas e respectivas ressignificações; g) Gestual de quem esmola ou solicita alguma coisa ou atenção.

Isto concorda com a citação: 
Os gestos dos mendigos são facilmente identificados: a mão que pede, o falar sozinho, o corpo curvado, o andar vagaroso, o olhar perdido, a cabeça baixa, o esbravejar, a gargalhada (ANA CLAUDIA HENRIQUES DE ARAUJO, P.837, 2013).

De acordo com a linha do tempo ao longo da HA, observamos obras de alguns renomados artistas, onde podemos citar:

1.Vincent Van Gogh, pintor, desenhista e gravador holandês retratou em seus quadros a miséria e o desespero de pessoas humildes que ele retrata como pessoas simples, com características rudes, sem embelezamento, traços grosseiros (mãos e faces) que podem ser observadas nas obras "Os Comedores de Batatas" (1885) (Fig. 1.1), "A Pair of Shoes" (1886) (Fig. 1.20), “A Pair of Shoes” (1887) (Fig.1.15), "Shoes" (1888) (Fig. 1.23) e "Three Pairs of Shoes" (1886) (Fig. 1.13); 2.Doménikos Theotokópoulos, conhecido como "El Greco", um importante arquiteto, pintor e escultor, de nacionalidade grega, que em estilo maneirista, dramatizava suas obras valorizando sentimentos e emoções através de temas religiosos retratando pessoas vivas. Na obra "São Martinho e o Mendigo" (15971599), óleo sobre madeira, o mendigo aparece desnudo, desprovido de vestes, enrolado em tecidos, em posição de submissão ao nobre cavaleiro (Fig. 1.2); 3.Pieter Brueghel, conhecido como "O velho", foi um importante gravurista e pintor renascentista de nacionalidade Flamenca que elaborava obras de contexto moral cotidiano, retratando a cultura popular (principalmente dos camponeses e aspectos sociais da vida no século XVI). Na obra "Os Mendigos" (1568), óleo sobre madeira, a composição mostra um conjunto de indivíduos, aleijados, formando ou fazendo alusão a exclusão pelo sistema capitalista da época (Fig. 1.3); 4.Bartolomé Esteban Murillo, foi um importante pintor de nacionalidade espanhola, que em estilo Barroco espanhol, retratava em suas obras de forma piedosa, a temática e os ideais religiosos e sociais da época. Nas obras "O Pequeno Mendigo" (1645), óleo sobre madeira (Fig. 1.16), "Os meninos Comendo Uvas e Melões" (1645-1646), óleo sobre tela (Fig. 1.7) e "Os Meninos Jogando Dados" (1645) óleo sobre madeira (Fig. 1.4), os mendigos são retratados na forma de crianças, que se encontram com vestimentas desgastadas e sobrepostas, pés descalços e rodeadas por objetos. Nestes dois últimos quadros o artista parece não querer evidenciar tanto a miséria e sim a leveza do momento contextual dos personagens, enquanto que na obra "Fray 
Junípero y El Mendigo" (1645-1646), óleo sobre madeira (Fig. 1.22), dramatiza sua obra valorizando a submissão, piedade ou emoção através do tema religioso, retratando o mendigo em uma forma jovem, parcialmente desnudo, enrolado em tecidos; 5.Rembrandt Van Rijn que no período barroco, através de suas gravuras explorou a imagem de mendigos, velhos de asilo e inclusive a própria figura como modelo de suas obras. Na obra "Mendigo Sentado e Seu Cachorro" (1629), gravura, o mendigo aparece como uma figura única, sentado, provido de vestes sobrepostas, associado a imagem de um animal doméstico, um elemento afetivo em sinônimo de companhia afetiva (Fig. 1.5), enquanto que na obra "Mendigo Lisiado" (1629), gravura, (Fig. 1.18) o mendigo também aparece como uma figura única, provido de vestes sobrepostas e representado através de uma figura portadora de deficiência física. Na obra "Beggars on the Doorstep of a House" (1648) (Fig. 1.8); 6.Pablo Ruiz y Picasso, pintor, escultor, ceramista cenógrafo, poeta e dramaturgo de nacionalidade espanhola, durante a fase azul, retratou a pobreza ou a morte, envolvendo os personagens por solidão, desespero e melancolia, fato este que esta relacionado a um período em que o artista se encontrava em dificuldades econômicas, frio e desespero. Na obra "Mendigo Junto ao Mar" (1903), óleo sobre tela, o artista insere a imagem de uma família de mendigos descalços, pensativos e com as vestes desgastadas, com corpos alongados (Fig. 1.6), enquanto que na obra "Velho Mendigo Com Um Menino" ou "Velho Judeu Com Um Menino" (1903) óleo sobre tela (Fig. 1.10) o artista insere a imagem de um velho associada a imagem de um menino que vive/mora nas ruas, ambos descalços, pensativos e com vestes desgastadas e corpos alongados. Segundo leituras há referencias sobre a perda da visão do próprio pai. Na obra “ O Velho Guitarrista Cego” (1903), óleo sobre tela, Picasso insere também a imagem de um velho, fazendo inferência a posição de um mendigo inclinada para frente (Fig. 1.14); 7.Diego Rivera, artista mexicano, conhecido como um dos principais executores de pinturas murais, na obra “Mi Vecino EI Mendigo" (1936), tempera e óleo sobre tela, aparece confraternizando com pessoas humildes (Fig. 1.9); 8.Dorotea Lange, uma influente fotografa documental e fotojornalista norte americana que fotografou a situação das ruas, obtendo imagens de desabrigados chamando a atenção de outros fotógrafos, levando-a trabalhar em uma instituição governamental com o objetivo de combater a pobreza rural, uma das principais consequências da grande depressão norte americana. Isto pode ser evidenciado na obra "Mãe Migrante, Nipomo, Califórnia" 
(1936) (Fig. 1.11); 9.-Francisco de Goya y Lucientes, importante gravador e pintor da realeza espanhola, que em estilo romântico retratava em suas obras a vida cotidiana de classes menos favorecidas da sociedade ou que sofriam as consequências de mudanças econômicas e sociais. Nas obras "Así, Suelen Acabar Lós Hombres Útiles", (1803-1824) aguada de Nankin sobre papel (Fig. 1.21) e "Mendigo Ciego Com Um Perro", (1801-1825) sépia papel (Fig. 12) os mendigos são retratados isoladamente na forma de abandono na velhice e na sociedade, dependência e esmolamento. Pode-se destacar nesta obra que a figura do mendigo está associada a imagem de um animal doméstico, um elemento afetivo em sinônimo de companhia; 10.Lasar Segal, pintor, escultor e gravurista de nacionalidade Lituana, ao longo de sua produção artística apresentou temas recorrentes como o universo dos desfavorecidos e marginalizados pela sociedade, preocupando-se com a violência, a miséria e as injustiças sociais em toda sua carreira. Na obra "O Mendigo" (1913), xilogravura sobre papel, o mendigo encontrase sentado, com a perna dobrada, cabeça caída e um objeto que pode ser um possível coletor de esmolas. (Fig. 17); 11.Honoré-Victorien Daumier, gravurista, escultor e pintor de movimento realista barroco francês, conferia as suas obras expressões de angustia e solidão, densidade e luminosidade através de temas da vida cotidiana, principalmente das classes populares e que foi considerado por Charles Buadelaire um dos melhores gravadores do seu tempo, enfocando a sátira política e social. Na obra "Os Mendigos", óleo sobre tela, os mendigos são retratados compondo um grupo, desprovidos aparentemente de vestimentas completas (Fig. 1.19).

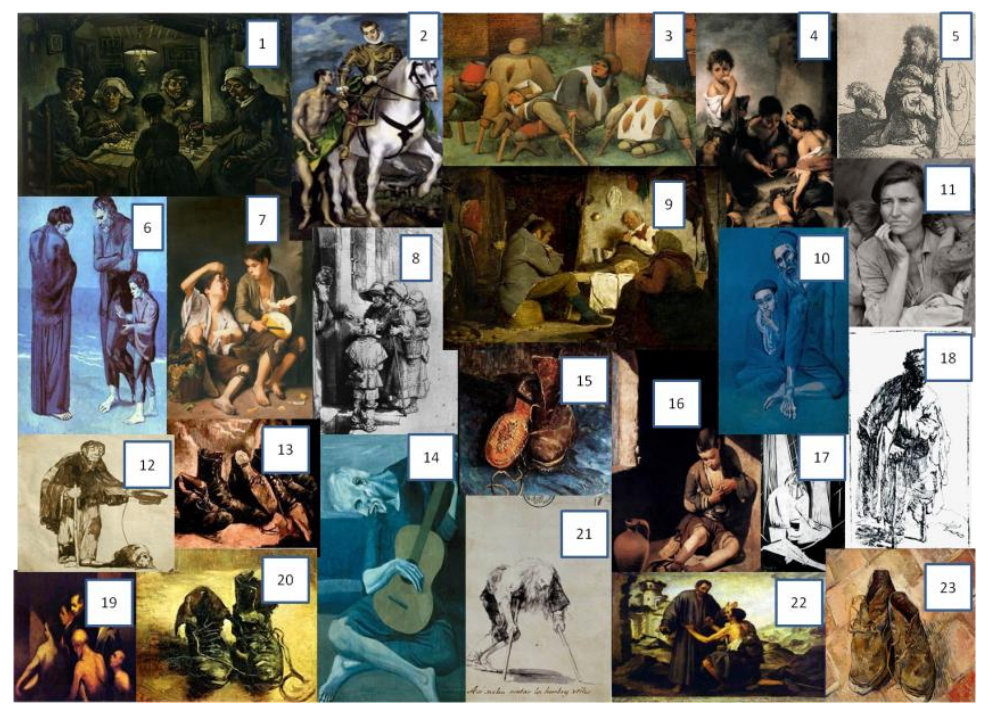

Figura 1. Representações relacionadas a "Pessoas em Situação de Rua" elaboradas por pintores e gravadores históricos (legenda em anexo) 
Acho pertinente citar outra diferente manifestação de uma relação entre corpo e deslocamento a partir da obra do artista belga Francys Alÿs "Sleepers" (1999-2006) (Fig. 2) e "Sleepers II" (2001) (Fig. 3) apresentada como vídeo instalação "Sleepers II" (1997-2002) (Fig. 4) constituída por oitenta lâminas tem como foco pessoas cujos corpos aparecem dormindo expostos diretamente a céu aberto e que são fotografados ao nível do solo pelo artista na Cidade do México, especialmente na área em torno de seu estúdio onde reside, revelando a habilidade que este artista tem de explorar artisticamente essa condição de vulnerabilidade social, mostrada ou explorada através do "corpo" e do cotidiano diário.

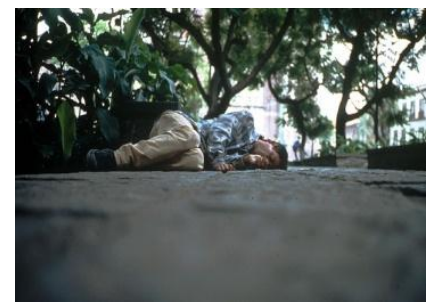

Figura 2. Sleepers - Francis Alÿs, 1999-2006

(Fonte:https://antonisiaschroder.wordpress.com/2011/11/12/francis-alys-sleepers/\#jp-carousel-114)

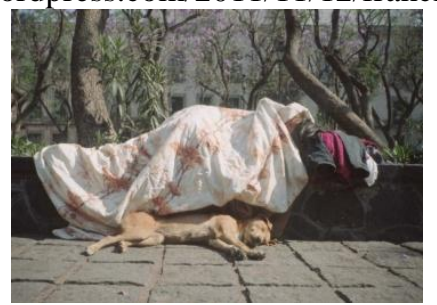

Figura 3. Sleepers II - Francis Alÿs, 2001

(Fonte: http://21 cblog.com/francis-alys-sleepers-ii-2001/)
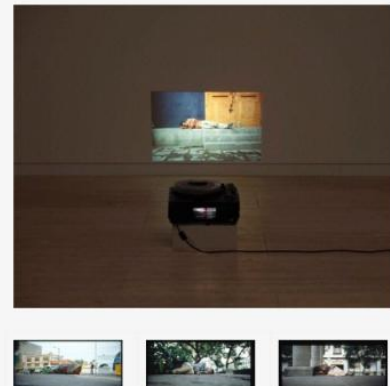

Figura 4. Sleepers II - Vídeo Instalação, Francis Alÿs, 2001

(Fonte: Http://www.artgallery.nsw.gov.au/collection/works/12011.24/)

A citação de Drouin (sem data) é aqui oportuna pois resume a produção deste artista. Relata que a obra de Francis Alÿs inspira uma serie de gestos para se infiltrar no fluxo da cidade, cujo centro histórico é chamado de "Território de Negligência" por causa da desordem e da degradação de seu tecido urbano. Vagando pelas cidades ele recolhe os elementos de uma memória visual que se concentra em imagens de pobreza. 
O trabalho idiossincrático de Francis Alÿs resiste a classificação. Englobando listas, planos e desenhos, performances (incluindo desfiles públicos e passeios solitários) e coleções de objetos provenientes de mercados de pulgas, o seu trabalho é inclusiva e plural e é muitas vezes inspirados por e localizados nas ruas da Cidade do México, onde o artista vive e trabalha."Sleepers II 'é formada a partir da ecologia colorido destas ruas que documentam as pessoas e os cães dormindo nas ruas, bancos e paragens de autocarro. Enquanto o trabalho poderia facilmente se presta a abordagem comentário social comemorativo do artista com o assunto mina tal interpretação. Abraçar a desordem ea abertura da Cidade do México, Alÿs comentou que: "Sleepers 'registra a maneira sonho pode ter um papel em um possível repensar do nosso convívio (SEM AUTOR1,http://www.artgallery.nsw.gov.au/collection/works/L2011.24/)

Outro artista que retrata uma temática relacionada a pessoas menos favorecidas ou que vivem as margens da sociedade é o destacado fotógrafo francês Mathieu Pernot, que produziu em 2009 uma série fotográfica a partir da situação de imigrantes afegãos obtidas no período da manhã (o que o artista considera em seu sono) no porto de Callais na França, intitulada "Les Migrants", considerados pelo artista como corpos reprimidos, escondidos, enrolados em tecidos, invisíveis, silenciosos e anônimos, reduzidos a sua simples forma, isolados a partir de um mundo que não os quer ver (Fig. 5).
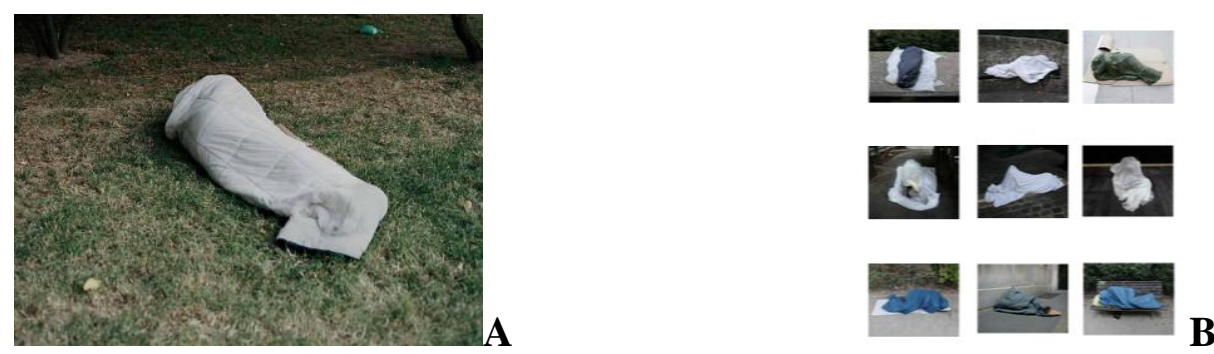

Figura 5. A. Les migrants, Mathieu Pernot, 2009

(fonte:http://www.histoire-immigration.fr/musee/collections/les-migrants; B. Les Migrants, Mathieu Pernot, (Fonte: http://www.mathieupernot.com/migrants.php)
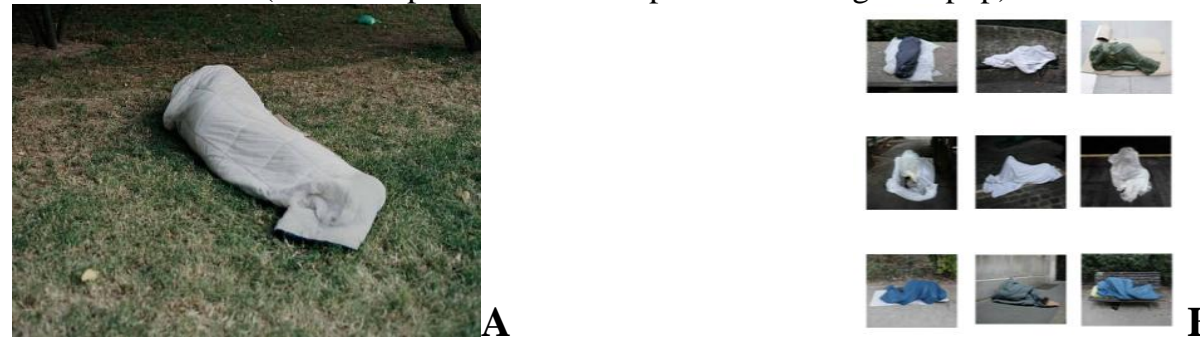

Figura 5. A. Les migrants, Mathieu Pernot, 2009

(fonte:http://www.histoire-immigration.fr/musee/collections/les-migrants;

B. Les Migrants, Mathieu Pernot, 2009

(Fonte: http://www.mathieupernot.com/migrants.php) 


\section{CONSIDERAÇÕES FINAIS}

Além de possibilitar minha investigação, a apresentação destas obras configura-se uma inserção da questão socioeconômica a poética visual partir do olhar onde o que eu pesquiso, faz com que a observação dessas imagens durante esta experiência tenha se constituído produto estético independente ou articulado com a pesquisa na arte contemporânea. Ao trazer questões sociais delicadas ao espaço institucional da arte através da diferentes formas de dar a ver o interesse pelas questões sociais e a simplicidade dos humildes ou quem sabe até dos humilhados, esfarrapados, pobres, deslocados socialmente e colocados a margem da sociedade, considero a necessidade da ressignificação de conceitos no intuito de aproximar os observadores, em um espaço institucional da arte, a partir da apropriação de uma estrutura (in)visível a percepção visual onde o material ou artefato rústico e sua resignificação relacionada ao espaço arte, passe a ser observado e visualizado como arte, independente de modismos e estilos e que este não seja visto somente como um(a) mendigo(a) ou artefato humano mas como vida, o outro que de alguma forma me afeta e que talvez possam ser legitimados como arte.

\section{REFERÊNCIAS}

ARAUJO, Ana Claudia Henriques de. Andrajos e Mendigos, Sinônimos de Visualidade. Monteiro, R. H. e Rocha, C. (orgs) 837-849. Anais do VI Seminário nacional de pesquisa em arte e cultura visual. Goiânia - GO:UFG, FAV, 2013.

BRANDAO, Ludmila de Lima. Deslocamentos contemporâneos: Notas sobre memória e arte. Revista Ciência e Cultura. São Paulo, v. 64, n 1, p. 58-61, jan. 2012. Disponível em: <http://cienciaecultura.bvs.br/pdf/cic/v64n1/20.pdf> Acesso em 29 nov. 2015.

CHARTIER, Roger. A construção estética da realidade - vagabundos e pícaros na idade moderna [2014 ou 2012]. Rio de janeiro: Editora Tempo, №17, PP 33-51. Disponível em: http://www.História.uff.br/tempo/artigos_dossie/artg17-3.pdf. Acesso em 10 dez. 2015.

DROUIN, Marianne. Francys Alÿs: Sleepers II. Disponível em: $<$ http://webcache.googleusercontent.com/search?q=cache:http://artsplastiques.acbordeaux.fr/isabelle/ALYS.htm\&gws_rd=cr\&ei=V21jVvCTO8mpwASyvrPADQ> Acesso em 29 nov. 2015 
JACQUES, Paola Berenstein. Elogio aos errantes. EDFBA: Salvador, 331p. 2012, Disponível em: <https://repositorio.ufba.br/ri/bitstream/ri/7894/1/Elogio_aos_Errantes_Rl(1).pdf> Acesso em 08 set. 2015

KASTRUPP, Virginia. O funcionamento da atenção no trabalho do cartógrafo In: Pistas do método da cartografia, Pesquisa-intervenção e produção de subjetividade. Porto Alegre: Sulina, 2009, 207p..p32-5. Disponível em: <http://www.editorasulina.com.br/img/sumarios/473.pdf>. Acesso em 10 out. 2015.

KUNZ, Gilderlândia Silva; HECKERT, Ana Lúcia; VASCONCELOS CARVALHO, Silvia. Modos de vida da população em situação de rua: inventando táticas nas ruas de Vitória/ES. Fractal, Revista de Psicologia, v.26, n.3, p. 919-942, set/dez 2014. Disponível em: <http://www.scielo.br/pdf/fractal/v26n3/0104-8023-fractal-2603-0919.pdf >Acesso em 10 de ago.2016.

MERLEAU - PONTY, Maurice. Fenomeologia da percepção, Martins Fontes: São Paulo, 657p. 1994. Disponível em: <http://charlezine.com.br/wpcontent/uploads/2011/11/Fenomenologia-da-Percep\%C3\%A7\%C3\%A3o-MerleauPonty.pdf> Acesso em: 13/05/2016.

MOURA, Carla Borin; HERNANDEZ, Adriane. Cartografia como método de pesquisa em arte. Anais do XI seminário de História da arte do centro de artes da Universidade Federal de Pelotas, UFPEL, 12p. 2012, Disponível em: https://periodicos.ufpel.edu.br/ojs2/index.php/Arte/article/view/1694 Acesso em 07 set. 2015.

ROLNIK, Suely. Cartografia ou de como pensar com o corpo vibrátil. Cartografia Sentimental, Transformações contemporâneas do desejo, Editora Estação Liberdade, São Paulo, 1989. Disponibilizado pela PUC - Núcleo de Estudos da Subjetividade. Disponível em: $<$ http://pucsp.br/nucleodesubjetividade/Textos/SUELY/pensarvibratil.pdf>. Acesso em 08/04/2016

SANTOS, Alexandre; SANTOS, Maria Ivone dos (Organizadores). A fotografia nos processos artísticos contemporâneos. Editora da Universidade Federal do Rio Grande do Sul (UFRGS): Porto alegre, 296p. 2004.

SANTOS, MILTON, A Natureza do Espaço, Técnica e Tempo. Razão e Emoção. 4 Ed. 2a reimpressão. São Paulo: Editora da Universidade de São Paulo EDUSP, 2006, 260p. Disponível em: <http://bibliodigital.unijui.edu.br:8080/xmlui/bitstream/handle/123456789/1799/A\%20 natureza\%20do\%20Espa\%C3\%83\%C2\%A7o.pdf?sequence=1pdf>. Acesso em 08/08/2015.

SEM AUTOR $1 . \quad$ Disponível em: http://www.artgallery.nsw.gov.au/collection/works/L2011.24/> Acesso em 20/05/2015

SILVEIRA, Paulo. A definição do livro-objeto. In: Entre ser um e ser mil: o objeto livro e suas poéticas. Edith Derdick (Org.) São Paulo: Editora SENAC, São Paulo, p. 19-31, 2013. 
TIBURI, Márcia, Ninguém mora onde não mora ninguém - Pequena reflexão sobre as pessoas abandonadas nas ruas das grandes cidades. Disponível em <http://revistacult.uol.com.br/home/2011/03/ninguem-mora-onde-nao-moraninguem/> Acesso em 12/04/2016.

\section{Apêndice 1 - Legenda das vinte e três representações relacionadas a "Pessoas em Situação de Rua" elaboradas por pintores e gravadores históricos}

Figura 1.1

Figura 1.2

Figura 1.3

Figura 1.4

Figura 1.5

Figura 1.6

Figura 1.7

Figura 1.8

Figura 1.9

Figura 1.10

Figura 1.11

Figura 1.12

Figura 1.13

Figura 1.14

Figura 1.15

Figura 1.16

Figura 1.17

Figura 1.18

Figura 1.19

Figura 1.20

Figura 1. 21

Figura 1.22
Os Comedores De Batatas - Vincent Van Gogh, 1885

http://estoriasdaHistória12.blogspot.com.br/2013/09/analise-da-obraos-

São Martinho e o Mendigo - El Greco, 1597-1599

http://virusdaarte.net/el-greco-sao-martinho-e-o-mendigo/ Os Mendigos - Pieter Brughel, 1568

http://www.auladearte.com.br/História_da_arte/brueghel.htm\#axzz3b5WVlHMb

Os Meninos Jogando Dados - Bartolomé Esteban Murillo, 1645

http://www.ufrgs.br/napead/repositorio/objetos/História-arte/idmod.php?p=murillo

Mendigo Sentado e Seu Cachorro - Rembrant Van Rijn, 1629

http://bomlero.blogspot.com.br/2013/07/a-arte-de-rembrandt.html

Mendigo Junto Ao Mar - Pablo Picasso, 1903

http://www.auladearte.com.br/História_da_arte/picasso. htm\#axzz3b5WV1HMb

Os Meninos Comendo Uvas e Melões - Bartolomé Esteban Murillo, 1645-1646)

http://www.ufrgs.br/napead/repositorio/objetos/História-arte/idmod.php?p=murillo

Beggars On The Doorstep Of A House - Rembrant Van Rijn, 1648

http://artify.gallery/product-page?ref=XIR239550

Mi Vecino El Mendigo - Diego Rivera, 1936

http://boverijuancarlospintores.blogspot.com.br/2014/11/erskine-nicol.html

O Velho Mendigo Com Um Menino - Pablo Picasso, 1903

http://www.ebah.com.br/content/ABAAAfgggAA/vida-obra-pablo-picasso

Mãe Migrante, Nipomo, California, 1936, Dorothea Lange, 1936 http://red032.com/dorothea-lange-18951965/

Mendigo Ciego Com Um Perro" - Francisco de Goya y Lucientes, 1801-1825

http://mismuseos.net/pt/comunidade/metamuseo/recurso/mendigo-ciego-con-un-perro/341989 c6ab-4ae3-81d9-29134caa5ed9

Three Pairs Of Shoes - Vincent Van Gogh, 1866

http://arteseanp.blogspot.com.br/2011/05/van-gogh-shoes-seus-significados.html

O Velho Guitarrista - Pablo Picasso, 1903

http://www.ebah.com.br/content/ABAAAfgggAA/vida-obra-pablo-picasso

A Pair Of Shoes - Vincent Van Gogh, 1887

http://arteseanp.blogspot.com.br/2011/05/van-gogh-shoes-seus-significados.html

O Pequeno Mendigo - Bartolomé Esteban Murillo, 1645

http://www.ufrgs.br/napead/repositorio/objetos/História-arte/idmod.php?p=murillo

O Mendigo - Lasar Segal, 1913 http://virusdaarte.net/segall-mendigo/

Mendigo Lisiado - Rembrant Van Rijn, 1629

http://www.galeriapremier.com.ar/articulos/18_REMBRANDT\%20VAN\%20RIJN/REMBRAN \%20VAN\%20RIJN.htm

Os Mendigos - Honoré-Victorien Daumier, 1845

http://es.wahooart.com/Art.nsf/Art_ES?Open\&Query=os,mendigos, Honoré

A Pair Of Shoes - Vincent Van Gogh, 1886

http://filosofianamadeiratorres.blogspot.com.br/2011/06/as-botas-de-van-gogh-texto-de-m.htr

Así, Suelen Acabar Lós Hombres Útiles - Francisco de Goya y Lucientes, 1803-1824

https://www.museodelprado.es/coleccion/galeria-on-line/galeria-on-line/obra/asi-suelenacabar-los-hombres-utiles-album-c-17/

Fran Junípero y El Mendigo - Bartolomé Esteban Murillo, 1645-1646

https://pt.wikipedia.org/wiki/S\%C3\%A3o_Jun\%C3\%ADpero\#/media/File:Bartolom\%C3\%A9

_Esteban_Murillo-_Brother_Juniper_and_the_Beggar.JPG 
Figura 1.23

Shoes - Vincent Van Gogh, 1888

http://arteseanp.blogspot.com.br/2011/05/van-gogh-shoes-seus-significados.html 